\title{
Neurologic alterations in an HIV adult patient with pertussis: a case report
}

\author{
María Camila Arango-Granados ${ }^{1,2^{*}}$ (D) and Iván Mauricio Trompa $a^{3,4}$
}

\begin{abstract}
Background: Pertussis is a highly contagious disease of public health interest caused by the bacterium Bordetella pertussis. Although its incidence has decreased substantially after the introduction of a vaccination, the burden of the disease remains high. Although the paroxysmal phase is highly disabling, complications are uncommon and more prevalent in children than in adults. The most frequent neurological complication is encephalopathy, but seizures, paresis, paraplegia, ataxias, aphasias, and decerebration postures have also been described. The complication of decerebration postures has not been previously reported in adults.

Case presentation: We present a video case of an adult HIV patient with severe coughing paroxysms, posttussive emesis and syncope, whose workup confirmed the diagnosis of a B. pertussis respiratory infection. During hospitalization, he had fluctuant encephalopathy and post-tussive decerebration postures following paroxysms. He was treated with antibiotic therapy and finally sent home without residual neurological deficits.

Conclusion: This case illustrates the biological plausibility of neurologic complications of pertussis in adults, which, albeit rare, can cause important morbidities. Future research should explore whether there are differences in the clinical presentation, risk factors and pathophysiology of the disease among adults or interventions aimed at preventing or treating pertussis encephalopathy.
\end{abstract}

Keywords: Whooping cough, Bordetella, Bronchopneumonia, Encephalopathy, Central nervous system infections, HIV, Acquired immunodeficiency syndrome

\section{Background}

Pertussis is a highly contagious disease of public health interest caused by the bacterium Bordetella pertussis. Although its incidence has decreased substantially after the introduction of a vaccination, the burden of the disease remains high [1]. Neurologic complications are not common and have been predominantly described in children [2-4]. We present a video case of encephalopathy and post-tussive decerebration postures in an adult HIV patient with a confirmed diagnosis of $B$. pertussis respiratory

\footnotetext{
* Correspondence: arango.mc@gmail.com

'Emergency Department, Fundación Valle del Lili, Cra 98 \# 18 - 49, Cali, Valle del Cauca, Colombia

${ }^{2}$ School of Medicine, Universidad Icesi, Cl. 18 \# 122 - 135, Cali, Valle del Cauca, Colombia

Full list of author information is available at the end of the article
}

infection. The patient provided written consent for publication of the information, images and videos related to his case.

\section{Case presentation}

A 49-year-old man from Medellín (Colombia) was previously diagnosed with human immunodeficiency virus (HIV) infection and currently adhered to an antiretroviral therapy regimen; he had a undetectable viral load and a CD4+ cell count $>400$ cells $/ \mathrm{mm}^{3}$ at presentation. The patient complained of 4 weeks of initial dry cough, low fever, coryza, conjunctival injection and rhinitis. Two weeks after symptom onset, the cough became paroxysmal and severe, with post-tussive emesis and occasional posttussive syncope (see video included as Additional file 1). No gastrointestinal or urinary symptoms were present.

(c) The Author(s). 2020 Open Access This article is licensed under a Creative Commons Attribution 4.0 International License which permits use, sharing, adaptation, distribution and reproduction in any medium or format, as long as you give appropriate credit to the original author(s) and the source, provide a link to the Creative Commons licence, and indicate if changes were made. The images or other third party material in this article are included in the article's Creative Commons licence, unless indicated otherwise in a credit line to the material. If material is not included in the article's Creative Commons licence and your intended use is not permitted by statutory regulation or exceeds the permitted use, you will need to obtain permission directly from the copyright holder. To view a copy of this licence, visit http://creativecommons.org/licenses/by/4.0/ The Creative Commons Public Domain Dedication waiver (http://creativecommons.org/publicdomain/zero/1.0/) applies to the data made available in this article, unless otherwise stated in a credit line to the data. 
The patient denied being previously vaccinated with Tdap (tetanus toxoid, reduced diphtheria toxoid, and acellular pertussis vaccine). He commented that his daughter and granddaughter had mild upper respiratory infections days before his symptoms started.

Upon admission, he had normal vital signs and no evidence of respiratory distress in the absence of cough. The laboratory results included a total leukocyte count of 13.030 cells $/ \mathrm{mm} 3$ with $56 \%$ neutrophils and $31 \%$ lymphocytes, hypoxemia on arterial blood gases (oxygen partial pressure of $59 \mathrm{mmHg}$ ) and a lactic dehydrogenase of $232 \mathrm{U} / \mathrm{L}$. The chest X-ray (Fig. 1) showed no clear evidence of alveolar occupation. Due to his past medical history, bronchoalveolar lavage (BAL) was performed, and samples were taken for gram staining, cultures and special stains. Polymerase chain reaction (PCR) for multiple respiratory pathogens was requested BIOFIRE $^{\circ}$ FILMARRAY $^{\circ}$ Respiratory Panel RP2). This assay searches for 4 bacteria (Bordetella pertussis [detection of ptxP], Bordetella parapertussis [detection of IS1001], Chlamydia pneumoniae and Mycoplasma pneumoniae) and 18 viruses (adenovirus, coronavirus 229E [CoV229E], coronavirus HKU1 [CoV-HKU1], coronavirus NL63 [CoV-NL63], coronavirus OC43 [CoV-OC43], human metapneumovirus [hMPV], human rhinovirus/enterovirus $[\mathrm{HRV} / \mathrm{EV})$, influenza virus A [FluA), influenza virus A H1 [FluA H1], influenza virus A H1-2009 [FluA H1-2009], influenza virus A H3 [FluA H3], influenza virus $B$ [FluB], parainfluenza virus 1 [PIV1], parainfluenza virus 2 [PIV2], parainfluenza virus 3 [PIV3], parainfluenza virus 4 [PIV4], respiratory syncytial virus [RSV] and Middle East respiratory syndrome coronavirus) [5].

Because of the chronicity of the cough, a computed tomography (CT) scan of the paranasal sinuses was

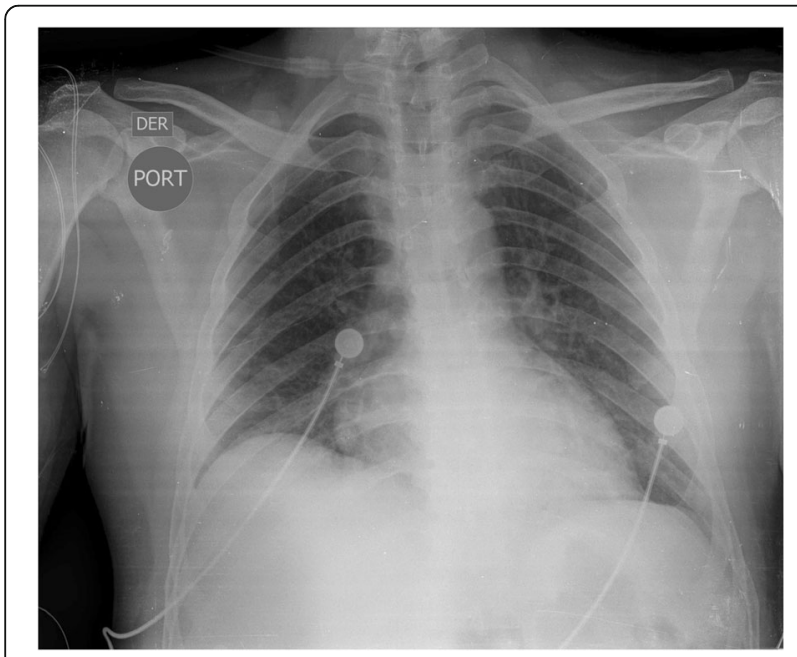

Fig. 1 Chest $X$-ray acquired on admission of an adult patient with suspected pertussis performed and revealed mucous thickening of all the sinuses due to chronic inflammation. Symptomatic management was initiated for chronic sinusitis, and clarithromycin was empirically started for a suspected pertussis-like syndrome. A day after admission, PCR for multiple respiratory pathogens confirmed the presence of $B$. pertussis. No other microorganisms were identified through this method. Other confirmation tests for $B$. pertussis were not performed given the $99-100 \%$ specificity of PCR [6] and the low yield of positive results with serology or culture techniques [7]. Common aerobic respiratory pathogens were not identified in the BAL cultures. Other opportunistic infections were excluded by special stains and laboratory tests on admission.

During his hospitalization, he continued to experience frequent paroxysmal cough (9 to 12 per day), with prolonged apnea, syncope and desaturation during the episodes. Additionally, his wife described that during the episodes his eyes deviated upwards, his arms became rigid while flexing his wrists, with subsequent myoclonic movements of both arms and legs (see video included as Additional file 2). The patient occasionally had diminished alertness and bradypsychia between coughing paroxysms. A careful evaluation excluded potential toxins or drug ingestion. In addition, the clear relationship between the coughing paroxysms and periods of full recovery without any neurological abnormalities precluded the need for lumbar puncture or neuroimaging. He finished a 7-day course of clarithromycin without requiring ventilatory support and without residual neurological deficits. He was finally sent home with persistent coughing paroxysms, although less severe and less frequent.

\section{Discussion and conclusion}

Pertussis or "whooping cough" is an acute respiratory disease caused by the gram-negative cocobacillus B. pertussis. This bacterium is a strict human pathogen that is transmitted through respiratory droplets. The disease is highly contagious [8]. There are nine recognized Bordetella species, but in addition to B. pertussis, only 3 of them have been associated with respiratory infections in humans: B. bronchiseptica, B. parapertussis, and B. holmesii [9]. This disease is more frequent in children than in adults, but there has been a recent increase in the incidence of the disease in previously vaccinated adults, possibly due to waning vaccine-induced immunity [2]. After the implementation of a vaccination in the 1940s, the incidence and mortality of pertussis were reduced by 92 and 99\%, respectively [10]. However, there are still approximately 48.5 million cases per year, with up to 295,000 deaths attributed to the disease [1].

The course of the disease can be described by 3 phases. The first phase is the catarrhal phase, which lasts approximately 1-2 weeks and is indistinguishable from 
other upper respiratory infections. However, in adults, excessive lacrimation and conjunctival injection can raise suspicion of pertussis [11]. In the next phase, the cough turns paroxysmal and is accompanied by inspiratory whooping that gives name to the disease. This, however, is a phenomenon rarely observed in adults. The presence of post-tussive emesis and post-tussive syncope is characteristic [2]. This phase can last between 2 weeks and 2 months $[11,12]$. Finally, during the convalescent phase, the cough gradually decreases in intensity, although it may be present for up to 2 months $[9,11]$.

Other microorganisms other than B. pertussis can produce a pertussis-like syndrome. The most frequently identified pathogens are rhinovirus/enterovirus (32.9\%), respiratory syncytial virus (31.4\%), parainfluenza virus (30.7\%), coronavirus (11.4\%), adenovirus (5.0\%), Mycoplasma pneumoniae (2.9\%), Chlamydia pneumoniae [13], B. parapertussis and B. holmesii [9].

Diagnostic suspicion of pertussis is rare in adults, especially since the presentation is not usually as classic as that in children. Paroxysmal cough in adults, for example, has a likelihood ratio (LR) + of 1.2 (1.04-1.7) and an LR - of 0.61 (0.52-0.72), which demonstrates its limited diagnostic utility [14]. Post-tussive vomiting has a similar diagnostic performance, with an LR + of 1.7 (1.32.3) and an LR - of 0.83 (0.73-0.93) [14]. Finally, classic whooping cough in adults is very rare, with a diagnostic sensitivity ranging from 16 to $28 \%$ [14].

PCR is an important tool for timely diagnosis of pertussis and is increasingly available to clinicians. There are several assays available that target different genetic sequences and therefore have different diagnostic performances. QIAstat-Dx RP, for example, targets the multicopy insertion sequence (IS481) that is present in multiple Bordetella species (B. pertussis, B. holmesii, and B. bronchiseptica) [15]. The BIOFIRE ${ }^{\oplus}$ FILMARRAY ${ }^{\bullet}$ Respiratory Panel used in this case is designed to be specific for the detection of $\mathrm{B}$. pertussis and targets the single-copy promoter region of the pertussis toxin gene $(p \operatorname{txP})$. Although the greater specificity $(99.3 \%)$ of the latter is accompanied by lower sensitivity [16, 17], a positive result supports the diagnosis of pertussis.

Complications are not common in adolescents and adults. However, cases of angina, carotid dissection, intracranial hemorrhage and fractures have been reported [2]. Encephalopathy is also a rare complication [3] that usually appears in the first 2 to 4 weeks after the onset of cough [4]. This complication occurs more frequently in nonvaccinated children $<2$ months, although it has also been described in adults [18]. The most frequent clinical manifestation is the onset of seizures, but paresis, paraplegia, ataxias, aphasias and decerebrating postures have also been described. The reason is believed to be penetration of Bordetella spp.-specific antigens to the central nervous system [3]. High levels of pertussis toxin (PT) and filamentous hemagglutinin (FHA) antibodies have been identified in the cerebrospinal fluid of these patients [3]. However, hypoxic encephalopathy secondary to apneas is also a possible cause of these manifestations [9].

To the best of our knowledge, this is the first reported case of a decerebrating posture caused by pertussis in an adult. It is unknown if there are differences in the clinical presentation, risk factors and pathophysiology of the disease among adults or if there are interventions aimed at preventing or treating pertussis encephalopathy. This case illustrates the biological plausibility of neurologic complications of pertussis in adults, which, albeit rare, can cause important morbidities.

Several antibiotics have in vitro activity against B. pertussis [19-21]. The first-line treatment of $B$. pertussis is macrolides, and oral erythromycin has been the mainstay of treatment over the past 30 years [9]. Antibiotics during the catarrhal stage appear to shorten the duration of symptoms and, in most cases, clear the organism from the upper respiratory tract within 5 days of the initiation of therapy [22, 23].

Erythromycin, a macrolide antibiotic, has been the antimicrobial of choice for treatment or postexposure prophylaxis of pertussis. It is usually administered in 4 divided daily doses for 14 days. Since erythromycin is accompanied by uncomfortable to distressing side effects that result in poor adherence to the treatment regimen two other macrolide agents (azithromycin and clarithromycin) are used for the treatment and prophylaxis of pertussis [23]. An alternate regimen is trimethoprimsulfamethoxazole [24].

Antibiotic therapy appears to be the most effective in the first 21 days after the onset of symptoms. After this time, there is uncertainty about the usefulness of antibiotics to improve the clinical outcomes [25]. Otherwise, management is generally symptomatic. However, there is doubtful evidence about the usefulness of diphenhydramine, dexamethasone, salbutamol or pertussis immunoglobulins in reducing coughing paroxysms. These interventions have still no proven efficacy in reducing the frequency of vomiting, frequency of whooping cough, frequency of cyanosis, development of serious complications, long hospital stays or mortality from any cause [26].

In severe cases, admission to the intensive care unit and invasive mechanical ventilation are required. Even extracorporeal membrane oxygenation and leukoreduction have been used for the management of pulmonary hypertension and cardiogenic shock secondary to the marked hyperleukocytosis that may accompany this disease $[27,28]$. However, the usefulness of leukoreduction or plasma exchange therapies is still a matter of debate. 
The case presented was not accompanied by hyperleukocytosis, which is observed in some severe cases [2931]. A probable explanation is the history of HIV infection; however, while current reports of B. pertussis and HIV infection describe the clinical characteristics of the disease [32, 33], the impact on the white blood cell count is unknown.

In conclusion, pertussis is a highly contagious disease of public health interest caused by the bacterium Bordetella pertussis. Although its incidence has decreased substantially after the introduction of a vaccination, the burden of the disease remains high. Although the paroxysmal phase is highly disabling, complications are uncommon and more prevalent in children than in adults. The most frequent neurological complication is encephalopathy, but seizures, paresis, paraplegia, ataxias, aphasias, and decerebration postures have also been described. To the best of our knowledge, this is the first reported case of a post-tussive decerebration posture caused by pertussis in an adult, which confirms the biological plausibility of neurologic complications of pertussis in this population. Future research should explore whether there are differences in the clinical presentation, risk factors and pathophysiology of the disease among adults or interventions aimed at preventing or treating pertussis encephalopathy.

\section{Supplementary information}

Supplementary information accompanies this paper at https://doi.org/10. 1186/s12879-020-05198-X.

Additional file 1. Coughing paroxysms in an adult patient with

confirmed pertussis

Additional file 2. Encephalopathy and decerebration postures in an adult patient with confirmed pertussis

\section{Abbreviations}

BAL: Bronchoalveolar lavage; PCR: Polymerase chain reaction; CT: Computed tomography; PT: Pertussis toxin; FHA: Filamentous hemagglutinin

\section{Acknowledgments}

Not applicable.

\section{Authors' contributions}

Both MCA and IMT participated as treating physicians in the case reported. MCA collected the information and videos related to the case and wrote the manuscript. IMT was a major contributor in writing the manuscript. Both authors reviewed and approved the final version of the manuscript.

\section{Authors' information}

María Camila Arango-Granados, MD, PGY3 Emergency Medicine Resident, Fundación Valle del Lili, Universidad Icesi, Cali, Valle del Cauca, Colombia. Iván Mauricio Trompa, MD, Infectious Diseases Specialist, IPS Universitaria León XIII, Universidad de Antioquia, Medellín, Antioquia, Colombia

\section{Funding}

The production of this manuscript was supported by the Infectious Disease Department of the IPS Universitaria León XIII (Medellín, Colombia). This department did not participate in the design, analysis, or interpretation of the data or in writing the manuscript.

\section{Availability of data and materials}

The datasets used and/or analysed during the current study are available from the corresponding author on reasonable request.

Ethics approval and consent to participate

This manuscript was approved by the IPS Universtaria León XIII Investigation Committee (Medellín, Colombia).

\section{Consent for publication}

The patient provided written consent for the publication of the information, images and video files related to his case.

\section{Competing interests}

The authors declare no competing interests.

\section{Author details}

'Emergency Department, Fundación Valle del Lili, Cra 98 \# 18 - 49, Cali, Valle del Cauca, Colombia. ${ }^{2}$ School of Medicine, Universidad Icesi, Cl. 18 \# 122 -

135, Cali, Valle del Cauca, Colombia. ${ }^{3}$ IPS Universitaria León XIII, Infectology Service, Cl. 69 \# 51C - 24, Medellín, Antioquia, Colombia. ${ }^{4}$ School of Medicine, Universidad de Antioquia, Cl. 67 \# 53 -108, Medellín, Antioquia, Colombia.

Received: 18 December 2019 Accepted: 24 June 2020

Published online: 02 July 2020

\section{References}

1. Crowcroft NS, Stein C, Duclos P, Birmingham M. How best to estimate the global burden of pertussis? Lancet Infect Dis. 2003;3(7):413-8.

2. Cornia PB, Hersh AL, Lipsky BA, Newman TB, Gonzales R. Does this coughing adolescent or adult patient have pertussis? JAMA. 2010;304(8): 890-6.

3. Grant CC, McKay EJ, Simpson A, Buckley D. Pertussis encephalopathy with high cerebrospinal fluid antibody titers to pertussis toxin and filamentous hemagglutinin. Pediatrics. 1998;102(4 Pt 1):986-90.

4. Zellweger H. Pertussis encephalopathy. Arch Pediatr. 1959;76:381-6.

5. Leber AL, Everhart K, Daly JA, Hopper A, Harrington A, Schreckenberger $P$, et al. Multicenter Evaluation of BioFire FilmArray Respiratory Panel 2 for Detection of Viruses and Bacteria in Nasopharyngeal Swab Samples. J Clin Microbiol. 2018;56(6):e01945-17.

6. Lee AD, Cassiday PK, Pawloski LC, Tatti KM, Martin MD, Briere EC, et al. Clinical evaluation and validation of laboratory methods for the diagnosis of Bordetella pertussis infection: culture, polymerase chain reaction (PCR) and anti-pertussis toxin IgG serology (IgG-PT). PLoS One. 2018;13(4):e0195979.

7. Gilberg S, Njamkepo E, Du Châtelet IP, Partouche H, Gueirard P, Ghasarossian C, et al. Evidence of Bordetella pertussis infection in adults presenting with persistent cough in a french area with very high whole-cell vaccine coverage. J Infect Dis. 2002;186(3):415-8.

8. Cherry JD, Heininger U. Pertussis and other Bordetella infections. Textbook of pediatric infectious diseases. 5th ed. Philadelphia: The W. B. Saunders Co; 2004. p. 1588-608.

9. Mattoo S, Cherry JD. Molecular pathogenesis, epidemiology, and clinical manifestations of respiratory infections due to Bordetella pertussis and other Bordetella subspecies. Clin Microbiol Rev. 2005;18(2):326-82.

10. Roush SW, Murphy TV, Group V-PDTW. Historical comparisons of morbidity and mortality for vaccine-preventable diseases in the United States. JAMA. 2007;298(18):2155-63.

11. Paisley RD, Blaylock J, Hartzell JD. Whooping cough in adults: an update on a reemerging infection. Am J Med. 2012;125(2):141-3.

12. Yaari E, Yafe-Zimerman Y, Schwartz SB, Slater PE, Shvartzman P, Andoren N, et al. Clinical manifestations of Bordetella pertussis infection in immunized children and young adults. Chest. 1999;115(5):1254-8.

13. Saiki-Macedo S, Valverde-Ezeta J, Cornejo-Tapia A, Castillo ME, PetrozziHelasvuo V, Aguilar-Luis MA, et al. Identfication of viral and bacterial etiologic agents of the pertussis-like syndrome in children under 5 years old hospitalized. BMC Infect Dis. 2019;19(1):75.

14. Ebell MH, Marchello C, Callahan M. Clinical diagnosis of Bordetella pertussis infection: a systematic review. J Am Board Fam Med. 2017;30(3):308-19.

15. Leber AL, Lisby JG, Hansen G, Relich RF, Schneider UV, Granato P, et al. Multicenter Evaluation of the QIAstat-Dx Respiratory Panel for Detection of 
Viruses and Bacteria in Nasopharyngeal Swab Specimens. J Clin Microbiol. 2020:58(5):e00155-20.

16. Jerris RC, Williams SR, MacDonald HJ, Ingebrigtsen DR, Westblade LF, Rogers BB. Testing implications of varying targets for Bordetella pertussis: comparison of the FilmArray respiratory panel and the focus B. pertussis PCR assay. J Clin Pathol. 2015;68(5):394-6.

17. Tatti KM, Wu KH, Tondella ML, Cassiday PK, Cortese MM, Wilkins PP, et al. Development and evaluation of dual-target real-time polymerase chain reaction assays to detect Bordetella spp. Diagn Microbiol Infect Dis. 2008; 61(3):264-72.

18. Halperin SA, Marrie TJ. Pertussis encephalopathy in an adult: case report and review. Rev Infect Dis. 1991;13(6):1043-7.

19. Hoppe JE, Haug A. Antimicrobial susceptibility of Bordetella pertussis (part I). Infection. 1988;16(2):126-30.

20. Hoppe JE, Eichhorn A. Activity of new macrolides against Bordetella pertussis and Bordetella parapertussis. Eur J Clin Microbiol Infect Dis. 1989; 8(7):653-4.

21. Hoppe JE. State of art in antibacterial susceptibility of Bordetella pertussis and antibiotic treatment of pertussis. Infection. 1998;26(4):242-6.

22. Bergquist SO, Bernander S, Dahnsjö H, Sundelöf B. Erythromycin in the treatment of pertussis: a study of bacteriologic and clinical effects. Pediatr Infect Dis J. 1987:6(5):458-61.

23. Tiwari T, Murphy TV, Moran J. National Immunization Program CDC. Recommended antimicrobial agents for the treatment and postexposure prophylaxis of pertussis: 2005 CDC Guidelines. MMWR Recomm Rep. 2005; 54(RR-14):1-16.

24. Hoppe JE, Halm U, Hagedorn HJ, Kraminer-Hagedorn A. Comparison of erythromycin ethylsuccinate and co-trimoxazole for treatment of pertussis. Infection. 1989;17(4):227-31.

25. Bennett J, Dolin R, Blaser M. Mandell, Douglas, and Bennett's principles and practice of infectious diseases. 9th ed. Philadelphia: Elsevier; 2020.

26. Bettiol S, Wang K, Thompson MJ, Roberts NW, Perera R, Heneghan CJ, et al. Symptomatic treatment of the cough in whooping cough. Cochrane Database Syst Rev. 2012;5:CD003257.

27. Rowlands HE, Goldman AP, Harrington K, Karimova A, Brierley J, Cross N, et al. Impact of rapid leukodepletion on the outcome of severe clinical pertussis in young infants. Pediatrics. 2010;126(4):e816-27.

28. Domico M, Ridout D, MacLaren G, Barbaro R, Annich G, Schlapbach LJ, et al. Extracorporeal membrane oxygenation for pertussis: predictors of outcome including pulmonary hypertension and Leukodepletion. Pediatr Crit Care Med. 2018;19(3):254-61.

29. Heininger U, Klich K, Stehr K, Cherry JD. Clinical findings in Bordetella pertussis infections: results of a prospective multicenter surveillance study. Pediatrics. 1997;100(6):E10.

30. Hodge G, Hodge S, Markus C, Lawrence A, Han P. A marked decrease in Lselectin expression by leucocytes in infants with Bordetella pertussis infection: leucocytosis explained? Respirology. 2003;8(2):157-62.

31. Carbonetti NH. Pertussis leukocytosis: mechanisms, clinical relevance and treatment. Pathog Dis. 2016;74(7):ftw087.

32. Nunes MC, Downs $\mathrm{S}$, Jones $\mathrm{S}$, van Niekerk N, Cutland CL, Madhi SA. Bordetella pertussis infection in south African HIV-infected and HIVuninfected mother-infant dyads: a longitudinal cohort study. Clin Infect Dis. 2016;63(suppl 4):S174-S80

33. du Plessis NM, Ntshoe G, Reubenson G, Kularatne R, Blumberg L, Thomas J, et al. Risk factors for pertussis among hospitalized children in a high HIV prevalence setting, South Africa. Int J Infect Dis. 2018;68:54-60.

\section{Publisher's Note}

Springer Nature remains neutral with regard to jurisdictional claims in published maps and institutional affiliations.

Ready to submit your research? Choose BMC and benefit from:

- fast, convenient online submission

- thorough peer review by experienced researchers in your field

- rapid publication on acceptance

- support for research data, including large and complex data types

- gold Open Access which fosters wider collaboration and increased citations

- maximum visibility for your research: over $100 \mathrm{M}$ website views per year

At BMC, research is always in progress.

Learn more biomedcentral.com/submissions 